\title{
Escrever, compor, cantar!: o encontro da literatura angolana com a música no combate ao colonialismo (1940-1950)
}

\author{
Amanda Palomo Alves \\ Instituto de Pesquisa e Memória Pretos Novos \\ Universidade do Estado do Rio de Janeiro
}

\begin{abstract}
Resumo
Este artigo objetiva, num primeiro momento, abordar o surgimento de movimentos literários em Angola que tiveram grande importância no processo de valorização da cultura nacional e de denúncia ao colonialismo português, particularmente entre os anos 1940 e 1950. Para tanto, destacamos a revista Mensagem e o movimento Vamos Descobrir Angola! — projetos lançados pelo poeta Viriato da Cruz — e abordamos também o surgimento e a trajetória do Movimento dos Novos Intelectuais de Angola (MNIA). Esse movimento, em especial, nos chama a atenção pelo fato de seus poetas e escritores estarem envolvidos num amplo empreendimento de recuperação da tradição oral do passado. Este é o segundo momento de nosso texto, em que assinalamos que poemas e provérbios produzidos por aquela geração de escritores passaram a receber melodia. Essa etapa é fundamental na história da música popular urbana de Angola.
\end{abstract}

Palavras-chave: Angola; literatura; música; resistência; colonialismo português.

Résumé

Cet article vise, dans un premier temps, à aborder l'émergence de mouvements littéraires en Angola qui ont eu une grande importance dans le processus de valorisation de la culture nationale et de dénonciation du colonialisme portugais dans les années 1940 et 1950. Pour cela, nous mettons en avant le magazine Message et le mouvement Découvrons Angola!, projets lancés par le poète Viriato da Cruz et nous abordons également l'émergence et la trajectoire du Mouvement des Nouveaux Intellectuels Angolais (MNIA). Ce mouvement, en particulier, attire notre attention parce que ses poètes et écrivains sont impliqués dans un grand effort pour retrouver la tradition orale du passé. C'est la deuxième partie de notre texte, où nous soulignons qu'au fil du temps, des poèmes et des proverbes produits par cette génération d'écrivains ont commencé à recevoir une mélodie, étape, celle-ci, fondamentale dans l'histoire de la musique populaire en Angola.

Mots-clés: Angola; littérature; musique; résistance; colonialisme.

Recebido em: 28/02/2020

Aprovado em: 01/09/2020 
Mas espera só quando esse comboio malandro descarrilar e os brancos chamarem os pretos p'ra empurrar. Eu vou, mas não empurro... António Jacinto. "Castigo pro comboio malandro", 1961.

Ao lançarmos nosso olhar aos países africanos de colonização portuguesa, observamos que a história de Portugal naquele continente é marcada por diversas formas de resistência, entre as quais a produção literária. Como recorda o historiador Elikia M'Bokolo, a escrita sempre foi um instrumento de luta contra os abusos do poder colonial, seja pelos livros, seja pelas peças de teatro, seja simplesmente por meio da produção de panfletos (M'BOKOLO, 2011). Ao nos direcionarmos para Angola, em particular, verificamos que são nos centros urbanos que nascem — através de jornais escritos por intelectuais angolanos - as primeiras denúncias à dominação colonial. Nesse contexto, duas associações, formadas no final dos anos 1920, se destacaram: a Liga Nacional Africana e o Grêmio Africano. Através delas surgiram as condições necessárias para que determinados grupos pudessem dar início a um processo de luta e de conscientização no interior de associações legais (ainda que atuassem de forma clandestina) a fim de buscarem estabelecer linhas e condutas de ação naquele contexto histórico tão particular.

Paralelamente a essa luta política (em grande medida, delimitada pelas áreas urbanas), grupos de estudantes das diversas colônias, que haviam emigrado para Lisboa a fim de realizarem seus estudos universitários, também se organizaram em torno de associações culturais legais. Durante as décadas de 1940 e 1950, aqueles jovens universitários, vindos das colônias de Angola, Moçambique, Cabo Verde, Guiné-Bissau e São Tomé e Príncipe se reuniam na metrópole com o objetivo de se organizarem e discutirem a situação colonial. É nesse contexto que surge na cidade de Lisboa, em 1951, o Centro de Estudos Africanos (CEA), que reuniria nomes importantes para história das independências africanas de colonização portuguesa: Amílcar Cabral, Agostinho Neto, Francisco José Tenreiro e Mário Pinto de Andrade. O governo salazarista pôs fim às atividades do centro, mas não pôde impedir os encontros daqueles estudantes que deram continuidade à luta política anticolonial na Casa dos Estudantes do Império (CEI) num processo de luta pela valorização do patrimônio histórico e cultural de seus povos.

Sabemos que uma forma de driblar a censura e as limitações impostas pelo colonialismo português foi a construção de uma visão nacionalista da cultura que objetivava "recuperar o patrimônio africano, sistematicamente relegado pelas autoridades coloniais ao esquecimento, por meio da fundação de revistas e jornais culturais" (BITTENCOURT, 2010, p. 134). Assim, no final dos anos 1940, uma significativa parcela da jovem intelectualidade luandense buscou se expressar por meio de textos literários e jornalísticos que reivindicavam os valores culturais nativos, então negados pelo colonialismo. É nesse período, especificamente em 1948, que surgem a revista Mensagem e o movimento Vamos Descobrir Angola!, ambos lançados pelo poeta angolano Viriato 
da Cruz. O primeiro número de Mensagem, de 1951, é dedicado aos jovens de Angola. Os autores elencam os objetivos do movimento e sinalizam suas propostas, entre as quais

a valorização e afirmação da cultura angolana; criar e levar a cultura de Angola alémfronteiras [...]; início de uma larga campanha de alfabetização dos "indígenas"; publicação periódica da revista Mensagem (de arte e cultura); realização de palestras, conferências, recitais e saraus literário-artísticos; criação de cursos livres de divulgação artística, literária ou científica; fundação de escolas primárias, médias e técnicas; criação de bibliotecas (MENSAGEM, 1951, p. 1-2).

Os escritores envolvidos com a revista Mensagem e com o movimento Vamos Descobrir Angola! se concentraram num projeto de recuperação e de valorização da cultura angolana pelo viés do texto literário. Porém, mais do que um projeto de reação ao "apagamento cultural" — imposto pelo colonialismo —, havia no projeto um explícito comprometimento político. Nessa fase, a influência da literatura brasileira foi fundamental, particularmente as obras dos modernistas Mário de Andrade e Manuel Bandeira e de escritores como José Lins do Rego e Jorge Amado. Aliás, segundo Rita Chaves, Jorge Amado preenchia "uma lacuna", tendo em vista que, sob sua óptica, nem a literatura colonial nem a literatura portuguesa estavam atentas aos problemas vivenciados pelos países africanos. Para Chaves, a literatura colonial investia no contrário, e a literatura portuguesa - mesmo aquela de cunho social - continuava ignorando o problema colonial e a discriminação. Neste contexto, "Jorge Amado chega com uma literatura voltada para os pobres, excluídos, injustiçados [...]. Ele cria, no fundo, personagens e ambientes que são familiares para uma África que ansiava por referências que não as coloniais" (AMADO, 2012, p. 10-11). Chaves explica também que toda a literatura colonial centrava, por exemplo, a questão do espaço no mato, ignorando a vida nas cidades africanas. Jorge Amado recupera isto ao trabalhar com espaços urbanos, como a cidade de Salvador.

Dois anos após a fundação da revista Mensagem e do movimento Vamos Descobrir Angola! surge o Movimento dos Novos Intelectuais de Angola (MNIA). Uma das características fundamentais do movimento era produzir uma poesia social. Nessa perspectiva, destacamos textos como "Mamá negra", de Viriato da Cruz, "Poema da alienação", de Antônio Jacinto, e "Muimbu ua Sabalu" (“Canção de Sabalu”), de Mário de Andrade. Este poema de Andrade, em

\footnotetext{
Após a conquista portuguesa de boa parte do território, no final da década de 1920, estabeleceu-se de forma definitiva a distinção oficial da população. Este processo implicou a classificação e delimitação dos espaços mais amplos da sociedade colonial angolana, surgindo assim os "civilizados" e os "indígenas", que incluíam, de um lado, os brancos, mulatos e negros "assimilados", por terem "absorvido padrões civilizados de conduta", e de outro lado, os "indígenas" que, por não terem alcançado tais padrões, permaneceriam sujeitos às arbitrariedades coloniais, como a proibição da posse da terra e o trabalho forçado (ALVES, 2015, p. 34).
} 
particular, foi escrito nos anos 1950 e é a primeira tentativa de utilização integral do quimbundo 2 na literatura angolana:

\author{
Mon'etu ua kasule \\ A mu tumisa ku S. Tomé \\ Kexiriê ni madukumentu \\ Aiué! \\ Mon'etu uaririle \\ Mama uasalukile \\ Aiué! \\ A mu tumisa ku S. Tomé
}

Mon'etu uai kiá

Uai um purá iá

Aiué!

A mu tumisa ku S. Tomé

Mon'etu a mu butu

K'atena ku mu kuta

Aiué!

A mu tumisa ku S. Tomé!

Mon'etu uolo banza

O’xi é o'nzo ié

A mu tuma kukalakala

Olo um tala, olo um tala.

-Mama, muene uondó vutuka

Ah! Ngongo ietu iondó biluka

Aiué

A mu tumisa ku S. Tomé

Mon'etu k'avutuké

Kalunga ua mu rié

Aiué!

A mu tumisa ku S. Tomé.

2 Quimbundo é a língua falada pelos povos ambundos, que constituíam a maioria dos habitantes de Luanda. Como explica Tony Hodges, Angola possui três grandes grupos etnolinguísticos. Os ovimbundos, cuja língua é o umbundo, concentravam-se, tradicionalmente, nas províncias do Huambo e do Bié, no planalto central. Os ambundos (falantes de quimbundo) predominaram nas regiões constituídas pelas atuais províncias de Bengo, Cuanza Norte, Luanda e Malange e pela parte norte do Cuanza Sul. O terceiro maior grupo étnico é o dos bacongos, que se estabeleceram principalmente nas províncias do noroeste, sendo sua língua o quicongo (HODGES, 2001, p. 44-46). 
O poema, que recebeu melodia do músico angolano Ruy Mingas, retrata o sofrimento de uma mãe que chora pelo desaparecimento do filho, então enviado como mão de obra forçada para as plantações de São Tomé. Sobre isso, cumpre destacar que com a diminuição das exportações de escravos, no século XIX, os comerciantes luandenses passaram a fazer um novo comércio com o interior baseado no marfim, na cera e na borracha. Outro caminho encontrado foi a exportação de mão de obra forçada para as plantações de São Tomé. O temor à exportação pelos chamados "serviçais" era muito grande devido à certeza de que não mais retornariam, pois eram conhecidos os maus-tratos e os perigos de não sobreviverem à viagem (BITTENCOURT, 1996). Em relação à utilização do quimbundo no poema, não se pode esquecer que línguas nativas de Angola, como o quimbundo, foram marginalizadas e marcadas com o "selo da inferioridade" (NETO, 1997, p. 338) durante o período colonial.

Um dos nomes mais representativos do MNIA foi certamente o do poeta Antônio Jacinto do Amaral Martins, mais conhecido como Antônio Jacinto. Em 1961, ano em que publica o seu primeiro livro, Poemas, é preso pela polícia política portuguesa, a PIDE, e enviado para o campo de concentração do Tarrafal, em Cabo Verde. "Monangamba", que descrevemos abaixo, é um dos textos publicados pelo poeta naquela obra:

\author{
Naquela roça grande \\ não tem chuva \\ é o suor do meu rosto \\ que rega as plantações. \\ Naquela roça grande \\ tem café maduro \\ e aquele vermelho-cereja \\ são gotas do meu sangue \\ feitas seiva. \\ O café vai ser torrado \\ pisado, torturado, \\ vai ficar negro, \\ negro da cor do contratado! \\ Perguntem às aves que cantam, \\ aos regatos de alegre serpentear \\ e ao vento forte do sertão: \\ Quem se levanta cedo? \\ Quem vai à tonga? ${ }^{3}$ \\ Quem traz pela estrada longa \\ a tipoia ou o cacho de dendê?
}

3 Do quimbundo: campo por lavrar; terreno; plantação, campina. 
Quem capina, quem paga recebe desdém

fubá podre, peixe podre,

pano ruim, cinquenta angolares ${ }^{4}$

"porrada se refilares"?

Quem faz o milho crescer?

e os laranjais florescerem?

Quem dá dinheiro para o patrão comprar

máquinas, carros, senhoras?

E cabeças de pretos para os motores?

Quem faz o branco prosperar?

ter barriga grande, ter dinheiro?

Quem?

$\mathrm{E}$ as aves que cantam,

os regatos de alegre serpentear

e o vento forte do sertão

responderão:

“Monangambééé"! (JACINTO apud FERREIRA, 1989, p. 39-41).

O poema também recebeu melodia de Ruy Mingas, um dos nomes mais representativos da história da canção popular urbana em Angola. Durante uma entrevista, no período de nossa pesquisa de campo em Luanda, Mingas afirmou: "Quando leio uma poesia bonita, procuro completá-la com uma melodia" (MINGAS, 2013). Ruy Mingas, sobrinho do lendário músico angolano, Liceu Vieira Dias, especializou-se em musicar poemas de escritores angolanos. "Monangambé", por exemplo, está presente em vários álbuns gravados pelo cantor entre os anos 1970 e 2000. Com relação ao poema, o pesquisador Alfredo Margarido sugere que o poema "pretende ultrapassar o plano do descritivo, embora aprofundado, e apresenta-se como um trabalho de encorajamento, de educação, que o incita a desafiar as leis que o reduzem a uma servidão" (MARGARIDO, 1980, p. 279).

Ao abordar o tema da violência, Antônio Jacinto explora a linguagem poética, recorrendo à metáfora e à ironia para denunciar a violência e a tensão social existentes entre colono e colonizado. No decorrer do poema, o colonizado passa a problematizar sua própria posição diante da sociedade. Tal tomada de consciência do eu lírico pode ser observada pela utilização de orações interrogativas durante o poema e através da repetição do pronome "quem" no transcorrer do texto. "Quem se levanta cedo?”; “Quem vai à tonga?”; “Quem faz o milho crescer e o branco prosperar?" São interrogações que desafiam a dinâmica da sociedade colonial, tão marcadamente

\footnotetext{
4 Angolar foi a unidade monetária que vigorou em Angola até 1956.
}

5 Do quimbundo: contratado. 
violenta e exploradora. Como destacou Lopes (2007), podemos perceber inclusive a atitude de ironia perante os questionamentos feitos pelo eu lírico do poema; afinal, até mesmo as aves, os regatos e o vento são capazes de responder: “Monangambééé...”! Opõem-se, segundo Lopes, àquilo que cabe ao trabalhador e ao que recebe o patrão: enquanto ao primeiro é oferecido fubá podre, peixe podre, pano ruim, ao segundo é reservado dinheiro, máquinas, carros, senhoras. Nesse caso, a distinção não se estabelece apenas pela diferença entre os bens materiais, mas também por elementos como humilhação e sentimento de superioridade (LOPES, 2007).

Com a intenção de fundar uma literatura que expressasse envolvimento com o contexto sociopolítico colonial, muitos escritores angolanos procuraram distanciar as suas produções literárias dos padrões europeus, recusando por vezes o texto estereotipado que lhes fora imposto pelo colonizador. Pensar numa literatura "essencialmente angolana", conforme afirma Margarido (1980), distanciada dos moldes impostos pela cultura eurocêntrica, deixava evidente o caráter combativo que permeava os ideais dos escritores angolanos daquela fase. Para o pesquisador, a história da literatura angolana pode ser dividida em dois grandes períodos. O primeiro deles está relacionado a certa "situação de dependência", em que o imaginário, ao mesmo tempo que apresenta características nacionais próprias, se submete a modelos estrangeiros. Assim, de acordo com essa perspectiva, as formas e os conteúdos dos textos são, por vezes, uma espécie de "reelaboração dos dados metropolitanos". A segunda fase é assinalada pelo "nascimento de uma consciência nacional", no qual a crítica ao colonialismo se configurava como o dado principal, tanto na forma como no conteúdo dos textos. Em poucas palavras, essa fase tinha "uma organização própria, essencialmente angolana” (MARGARIDO, 1980, p. 331).

O contexto histórico, a situação sociopolítica e a expressão literária angolana são, portanto, aspectos profundamente imbricados. $\mathrm{Na}$ tentativa de valorizar a cultura nacional os escritores da "geração dos anos 1950", como são também reconhecidos, passaram a escrever sobre as questões específicas vivenciadas em Angola, sendo o combate ao colonialismo um dos motes principais. Recusando de maneira contundente os padrões europeus que até então haviam sido o eixo regulador das produções literárias angolanas, a poesia e a prosa se reconfiguraram e começaram a apresentar profundas transformações não apenas nas temáticas abordadas, mas também na estrutura textual. O recurso ao quimbundo, assim como as deformações fonéticas do português, por exemplo, sinaliza a busca por uma semântica angolana. "Ao evitar os procedimentos que conduziriam ao exótico e/ou ao pitoresco, os poetas optam pela aproximação com a terra e a cultura angolanas numa relação produtiva que afasta a clicherização" (CHAVES, 1999, p. 46). Desse modo, a partir da década de 1950, começa a ganhar destaque "tudo que traz o traço da alteridade angolana" (MACÊDO, 2008, p. 33).

A colônia começa a tornar-se sujeito de sua história. Iniciam-se os movimentos em prol da autonomia com o engajamento decisivo dos letrados. Esse momento engendra uma literatura cuja marca é a tensão entre a negação dos modelos técnico-formais do 
colonizador e a fundação de uma nova escrita, cujo traço é a proposta de nacionalismo: no vocabulário, nas situações retratadas, no novo ângulo com que é focalizada a relação colônia/metrópole (MACÊDO, 2008, p. 33-34).

Em 1951, o MNIA realizava seu primeiro (e último) concurso literário. Num dos sarais promovidos pelo movimento, os poetas vencedores do concurso recitaram seus poemas. Porém, naquele dia, a leitura do poema "Bandeira", de Maurício Gomes, não foi permitida, pois incomodou bastante as autoridades coloniais da época. Os versos inicias e finais do texto enunciam:

Somos um povo à parte

Desprezado

Incompreendido

Um povo que lutou e foi vencido.

Por isso, em meu canto de fé,

Clamo e proponho, Negro,

Que a nossa bandeira

Seja um pano negro,

Negro da cor da noite sem luar...

Sobre essa escuridão de luto e de pesar,

Da cor da nossa cor,

Escreve, irmão,

Com a tua mão rude e vacilante

- Mas forte -

A palavra-força: União!

[...]

A palavra suprema: LIBERDADE!

À volta dessas palavras-alavancadas

Semeia estrela às mãos-cheias,

Todas rútilas,

Todas de primeira grandeza,

Estrelas belas de nossa Esperança

Estrelas lindas da nossa Fé

Estrelas que serão certeza na nossa BANDEIRA!

O texto faz alusão às cores que estariam presentes na bandeira de um dos principais movimentos de libertação angolanos, o Movimento Popular de Libertação de Angola (MPLA). ${ }^{6}$

6 Bittencourt (2002) explica que o MPLAé o resultado da agitação anticolonial iniciada no final dos anos 1940, mas que se prolongou por toda a década de 1950. Sua formação decorre de duas correntes nacionalistas constituídas pelos que estavam na colônia, conhecidos como "os do interior", e pelos que se encontravam na metrópole, em demais países europeus e, mais raramente, em países africanos. Todos esses ficariam conhecidos como "os do exterior". MacQueen (1998) complementa, ao esclarecer que o movimento — dirigido inicialmente por Viriato da Cruz e Mário de Andrade — recebeu, desde a sua fundação, o apoio de africanos urbanizados e de mestiços que estavam concentrados sobretudo na região de Luanda. 
Passado algum tempo, o MNIA foi alvo de contundentes repressões policiais, e na mesma época a revista Mensagem findou precocemente suas atividades, logo após a publicação de seu segundo número. Apesar da curta existência, a revista representou um verdadeiro símbolo de contestação ao regime colonial. Os poetas e escritores da "geração Mensagem" engajaram-se, cada vez mais, na luta política, aberta e clandestina, e naquela mesma década novos e importantes escritores ingressaram na Sociedade Cultural de Angola, ${ }^{7}$ na Associação dos Naturais de Angola e na Casa dos Estudantes do Império.

Tanto a Mensagem quanto os movimentos literários não dispunham de um programa político de luta contra as autoridades coloniais, mas foram fundamentais enquanto elementos mobilizadores e de conscientização daqueles que, futuramente, iriam encabeçar a luta anticolonial. Foi essencialmente por meio da poesia que o seleto grupo de jovens escritores se impôs e contribuiu para a história da literatura angolana. Assim, a obra produzida pelos escritores do MNIA buscou enaltecer o cotidiano vivido pelos nativos de Angola, valorizando suas línguas, costumes e crenças. Para alcançar tais objetivos, os escritores se engajaram numa série de atividades culturais e sociais, como campanhas de alfabetização, fundação de escolas e bibliotecas, criação de concursos literários e lançamento de revistas. $\mathrm{O}$ empenho dos envolvidos foi ainda mais significativo ao levar em conta que a palavra escrita chegava, naquela época, a uma parcela ínfima da população de Angola. Em 1958, por exemplo, o número de analfabetos (entre negros e mestiços) era de 4.009.911, representando aproximadamente $96,7 \%$ da população total. ${ }^{8}$

Atentos a esses números e condições, os escritores do MNIA tiveram uma ideia muito bem resumida por Silva (2012): "pintar o texto literário com harmonia, melodias e ritmos" (p. 141-142), para que os textos (e suas respectivas e importantes mensagens) pudessem atingir, de maneira direta, a população nativa e analfabeta. Além disso, para os poetas daquela geração, musicar um poema passou a ser uma nova maneira de trazer, para a oralidade, seus sonhos e ideais. Um exemplo deste esforço pode ser percebido no poema "Castigo pro comboio malandro". 9

\author{
Esse comboio malandro passa \\ passa sempre c'oa força dele \\ ué-ué-ué; hi-hi-hi; te-que-tem te-que-tem \\ O comboio malandro passa \\ nas janelas, muita gente \\ ah boa viagée, adeus homée
}

\footnotetext{
7 Em 1957, a Sociedade Cultural de Angola reinicia a publicação de seu jornal, Cultura. Durante dois anos, período em que foi permitida a circulação do jornal, foram publicados doze números, contendo textos científicos e literários escritos exclusivamente por angolanos (ERVEDOSA, 1979).

8 Informações do Anuário Estatístico de Angola, 1958. Luanda. Ano XXIV, p. 19-21 (apud NORÉ; ADÃO, 2003, p. 105).

9 O poema recebeu a melodia do músico e compositor Fausto Bordalo, que gravou a canção no álbum $A$ preto $e$ branco, de 1989.
} 
n'ganas bonitas

quintandeiras de lenço encarnado

levam cana no Luanda p'ra vender

hi-hi-hi

naquele vagon de grades tem bois

mú-mú-mú.

Tem outro igual

com este dos bois

leva gente muita gente como eu

cheio de poeira gente triste

gente triste como os bois

gente que vai no contrato.

Tem bois que morre no viagée

mas um preto não morre

canta como é criança

mulondé iakessoa!

uadibalée, uadibalée, uadibalée, uadibalée

esse comboio malandro

sozinho na estrada de ferro passa

passa sem respeito

ué-ué, hi-hi

com muito fumo no trás

tem-que-tem tem-que-tem.

Comboio malandro

o fogo que sai no corpo dele

vai no capim e queima

vai nas casas,

vai nas casas dos preto e queima

esse comboio malandro

esse comboio

esse comboio malandro

já queimou o meu milho.

Se na lavra do milho

tem pacaças

eu faço armadilhas no chão

se na lavra tem Kiombos

eu tiro espingarda de Kimbundo

e mato neles!

Mas se vai lá fogo

de comboio malandro deixa

ué-ué-ué, tem-que-tem tem-que-tem

só fica fumo

muito fumo mesmo... ué-ué-ué 


\begin{abstract}
Mas espera só
quando esse comboio malandro descarrilar e os brancos chamar os pretos p'ra empurrar eu vou... mas não empurro.
\end{abstract}

Nem com o chicote

finjo só que faço força

comboio malandro

você vai ver só o castigo

vai dormir mesmo no meio do caminho!

você vai ver só o castigo

vai dormir mesmo no meio do caminho!

ué-ué-ué! (JACINTO, 2004, p. 23-24).

Existe uma tentativa do autor de assumir os recursos que valorizam a sonoridade, seja pelo uso da mistura das línguas portuguesa e quimbunda, pela repetição de palavras ou pelo uso intencional de onomatopeias: "ué-ué-ué; tem-que-tem-tem-que-tem". Todos esses elementos contribuem para dar "harmonia e ritmo" ao poema, auxiliando na percepção do leitor-ouvinte que passa a compreender de outra maneira a poesia de Antônio Jacinto, cuja obra reflete, esteticamente, os ideais do MNIA (SILVA, 2012). Quando o músico Fausto Bordalo interpreta o poema "Castigo pro comboio malandro", ele hibridiza o domínio da linguagem e o da música. Este movimento gera, segundo Silva (2012), o blend space constituído pela mistura dos domínios musical e o da linguagem, trazendo assim para o leitor-ouvinte uma "imagem sensório-cognitiva" muito mais abrangente (p. 146).

Viriato da Cruz é outro nome importante na história do MNIA. O escritor, nascido em Porto Amboim, Angola, teve vários de seus poemas musicados, entre os quais "Makezu", ${ }^{10}$ canção interpretada e gravada por Ruy Mingas e, também, pelo emblemático grupo musical angolano "N'gola Ritmos"."11

${ }^{10}$ Makezu, em quimbundo, significa noz-de-cola, elemento religioso importante para diferentes povos de Angola.

${ }^{11}$ Canção integrante da trilha sonora do documentário O ritmo do N'gola Ritmos, de António Ole, 1978. O conjunto foi fundado no final dos anos 1940 por Liceu Vieira Dias, muito conhecido em Angola como "Tio Liceu". A preocupação de seus integrantes em divulgar a cultura dos antepassados num período no qual as canções, línguas e culturas tradicionais de Angola eram rejeitadas pelo sistema colonial é uma das principais marcas do conjunto. Com a prisão, pela PIDE, de dois de seus principais componentes - Liceu Vieira Dias e Amadeu Amorim - , o N'gola Ritmos entraria em outra fase e com outra formação, que teria início apenas na década de 1960 (ALVES, 2015; 2016). Para o pesquisador e crítico musical angolano, Jomo Fortunato (2009b), os integrantes do N'gola Ritmos podem ser considerados pioneiros da modernidade estética da música angolana, no sentido das propostas inovadoras e de estilização do cancioneiro popular. O músico brasileiro Martinho da Vila também fez uma interpretação do poema de Viriato da Cruz; a canção "Makezu" foi gravada no álbum 3.0 Turbinado, em 1998. 
“Kwa kyé! Makezu, Makezwé...”!

O pregão da avó Ximinha

É mesmo como os seus panos,

Já não tem a cor berrante

Que tinha nos outros anos.

Avó Xima está velhinha,

Mas de manhã,

manhãzinha,

Pede licença ao reumático

E num passo nada prático

Rasga estradinhas na areia...

Lá vai para um cajueiro

Que se levanta altaneiro

No roteiro dos caminhos

Das gentes que vão pr'a Baixa.

Nem criados, nem pedreiros

Nem alegres lavadeiras

Dessa nova geração

Das "venidas de alcatrão"

Ouvem o fraco pregão

Da velhinha quitandeira.

“Kwa kyé! Makezu, Makezwé!” (DA CRUZ, 1961).

O poema nos conta a história da "Avó Ximinha", uma matriarca angolana, quitandeira e vendedora de makezu. Os povos que viviam afastados dos grandes centros de Angola costumavam comer o makezu logo quando amanhecia, mas a "nova geração", apontada no poema, parece interferir na tradição local e mal ouvem o pregão "da velhinha quitandeira". Outra característica a destacar é a utilização do bilinguismo, que, assim como em Viriato da Cruz, é algo constante na obra de grande parte dos poetas envolvidos com o MNIA.

Hampâté Bâ constata que as sociedades africanas são "sociedades da palavra" (2010, p. 167 e 212), e, ao pensarmos na musicalidade africana, especificamente, percebemos que ela se inscreve nos espaços da comunidade, pois possibilita e instaura formas de sociabilidade. A música surge, nesse caso, como um elemento essencial nas reuniões comunitárias e coletivas, segundo o pesquisador e crítico musical angolano Jomo Fortunato (2009a). Em Angola a música tradicional, do espaço rural, se caracterizava, essencialmente, pelo anonimato na composição, ou seja, a noção de autoria estava anulada pelo tempo. Com o passar dos anos, os poemas e os provérbios começaram a receber melodia, e as composições musicais aceitas enquanto produções coletivas no interior das comunidades, e passaram a ser transmitidas oralmente, de geração em geração (FORTUNATO, 2009a). 
Neste artigo, buscamos demonstrar, entre outros aspectos, que os poemas e a produção literária, os textos jornalísticos, as denúncias escritas por intelectuais, os movimentos sociais e culturais e a musicalidade são elementos de fundamental importância para o entendimento da história recente de Angola. No final dos anos 1940 e início dos anos 1950 surge uma geração de escritores preocupada em expressar, por meio de poesias e textos literários, as condições de opressão a qual os povos da colônia estavam submetidos. De modo inovador e, até mesmo, "revolucionário", aquela geração de escritores, especialmente intelectuais e literatos envolvidos com o MNIA, deu início à prática de "musicar poemas", uma alternativa de trazer, para a oralidade, suas angústias e aspirações, mas sobretudo de transmitir aos angolanos que não tinham acesso à palavra escrita mensagens de esperança e de luta.

\section{Referências}

ALVES, Amanda Palomo. Angolano segue em frente: um panorama do cenário musical urbano de Angola entre as décadas de 1940 e 1970. 2015. 216 f. Tese (Doutorado em História). Niterói, Universidade Federal Fluminense, 2015.

. Oh, Muxima! A formação da música popular urbana de Angola e o grupo "N'gola Ritmos" (1940-1950), TEL: Tempo, Espaço, Linguagem, Irati, v. 7, n. 2, p. 193-218, jul./dez. 2016.

AMADO, Jorge. [Entrevista cedida a] Rita Chaves e Inocência da Matta, O Chá: Mensário Angolano de Cultura, 2. série, ano 1, n. 1, p. 10-11, 2012.

BITTENCOURT, Marcelo. As linhas que formam o "EME”: um estudo sobre a criação do Movimento Popular de Libertação de Angola. 1996. 196 f. Dissertação (Mestrado em Antropologia). São Paulo, Universidade de São Paulo, 1996.

.Estamos juntos: o MPLA e a luta anticolonial (1961-1974). 2002. 742 f. Tese (Doutorado em História). Niterói, Universidade Federal Fluminense, 2002.

Angola: tradição, modernidade e cultura política. In: REIS, Daniel A. et al. (org.). Tradições e modernidades. Rio de Janeiro: Editora da FGV, 2010. p. 129-144.

CHAVES, Rita. A formação do romance angolano: entre intenções e gestos. São Paulo: FBLP/ Via Atlântica, 1999.

DA CRUZ, Viriato. Obra poética: poemas. Lisboa: Casa dos Estudantes do Império, 1961.

ERVEDOSA, Carlos. Roteiro da literatura angolana. Lisboa: Edições 70, 1979.

FERREIRA, Manuel. 50 poetas africanos. Lisboa: Plátano, 1989.

FORTUNATO, Jomo. Processo de formação da música popular angolana, Jornal de Angola, 19 out. 2009a. Disponível em: http://jornaldeangola.sapo.ao/cultura/musica/processo_de_ formacao_da_musica_popular_angolana. Acesso em: 28 fev. 2020.

A modernidade estética da música angolana, Jornal de Angola, 16 nov. 2009b. Disponível em: http://jornaldeangola.sapo.ao/cultura/a_modernidade_estetica_da_musica_ angolana. Acesso em: 28 fev. 2020. 
HAMPÂTÉ BÂ, Amadou. A tradição viva. In: KI-ZERBO, J. (org.). História geral da África I: metodologia e pré-história da África. Brasília: Unesco, 2010. p. 167-214.

HODGES, Tony. Angola: do afro-estalinismo ao capitalismo selvagem. Cascais: Principia, 2001. JACINTO, António. [1961]. Poemas. Luanda: Maianga, 2004.

LOPES, Rosely Z. Barbosa. A poesia de António Jacinto, Crioula: revista eletrônica dos alunos de pós-graduação em Estudos Comparados de Literaturas de Língua Portuguesa da Universidade de São Paulo, n. 1, p. 1-6, 2007.

M'BOKOLO. África negra: história e civilização. Salvador/São Paulo: EDUFFBA/Casa das Áfricas, 2011. Tomo II.

MACÊDO, Tania. Luanda, cidade e literatura. São Paulo/Luanda: Editora da UNESP/ Nzila, 2008.

MACQUEEN, Norrie. A descolonização da África portuguesa: a revolução metropolitana e a dissolução do império. Lisboa: Editorial Inquérito, 1998.

MARGARIDO, Alfredo. Estudos sobre literaturas das nações africanas de língua portuguesa. Lisboa: A regra do jogo, 1980.

MENSAGEM: a voz dos naturais de Angola. Luanda, Departamento Cultural da Associação dos Naturais de Angola, ano 1, 1951.

MINGAS, Ruy. [Entrevista cedida a] Amanda Palomo Alves. Luanda, 4 nov. 2013.

NETO, Maria da Conceição. Ideologias, contradições e mistificações da colonização de Angola no século XX, Lusotopie, n. 4, p. 327-359, 1997.

NORÉ, Alfredo; ADÃO, Áurea. O ensino colonial destinado aos "indígenas" de Angola: antecedentes do ensino rudimentar instituído pelo Estado Novo, Revista Lusófona de Educação, Lisboa, n. 1, p. 101-126, 2003.

SILVA, Emanuela F. Ferreira. A pintura do poema "Castigo pro comboio malandro" de Antônio Jacinto: domínio musical e da linguagem como forma de encenar a construção da nacionalidade, SCRIPTA, Belo Horizonte, v. 16, n. 31, p. 139-148, 2. sem. 2012.

\section{Minicurrículo}

Amanda Palomo Alves é doutora em História Social pela Universidade Federal Fluminense, com mestrado em História (UEM) e em Relações Étnico-Raciais (Cefet-RJ) e estágio Pósdoutorado em História (Unioeste). Nos últimos anos tem-se dedicado aos seguintes temas de pesquisa: História da África no Século XX (particularmente, Angola); Ensino de História; Educação para as Relações Étnico-Raciais e Música. 